\title{
Epidermal growth factor receptor mutations and anaplastic lymphoma kinase rearrangements in lung cancer with nodular ground-glass opacity
}

\author{
Sung-Jun $\mathrm{Ko}^{1}$, Yeon Joo Lee ${ }^{1,2}$, Jong Sun Park ${ }^{1,2}$, Young-Jae Cho ${ }^{1,2}$, Ho II Yoon ${ }^{1,2}$, Jin-Haeng Chung ${ }^{3}$, \\ Tae Jung Kim", Kyung Won Lee ${ }^{4}$, Kwhanmien Kim, Sanghoon Jheon ${ }^{5}$, Hyojin Kim', Jae Ho Lee ${ }^{1,2}$ \\ and Choon-Taek Lee ${ }^{1,2^{*}}$
}

\begin{abstract}
Background: Nodular ground-glass opacities ( $\mathrm{nGGO}$ ) are a specific type of lung adenocarcinoma. ALK rearrangements and driver mutations such as EGFR and K-ras are frequently found in all types of lung adenocarcinoma. EGFR mutations play a role in the early carcinogenesis of $\mathrm{nGGOs}$, but the role of ALK rearrangement remains unknown.

Methods: We studied 217 nGGOs resected from 215 lung cancer patients. Pathology, tumor size, tumor disappearance rate, and the EGFR and ALK markers were analyzed.

Results: All but one of the resected nGGOs were adenocarcinomas. ALK rearrangements and EGFR mutations were found in $6(2.8 \%)$ and 119 (54.8\%) cases. The frequency of ALK rearrangement in nGGO was significantly lower than previously reported in adenocarcinoma. Advanced disease stage $(p=0.018)$ and larger tumor size $(p=0.037)$ were more frequent in the ALK rearrangement-positive group than in ALK rearrangement-negative patients. nGGOs with ALK rearrangements were associated with significantly higher pathologic stage and larger maximal and solid diameter in comparison to EGFR-mutated lesions.
\end{abstract}

Conclusion: ALK rearrangement is rare in lung cancer with nGGOs, but is associated with advanced stage and larger tumor size, suggesting its association with aggressive progression of lung adenocarcinoma. ALK rearrangement may not be important in early pathogenesis of nGGO.

Keywords: Lung cancer, Adenocarcinoma, nGGO, ALK, EGFR

\section{Background}

Low-dose chest computed tomography (CT) for lung cancer screening has increased the detection of solitary pulmonary nodules (SPN) not visualized on chest radiography, and has contributed to a reduction in lung cancer mortality [1]. Some of these visualized nodules are nodular ground-glass opacities (nGGOs). nGGOs on chest CT are defined as hazy, increased attenuation of the lung with preservation of bronchial and vascular margins, and are classified as pure and mixed GGOs, which contain a solid component [2].

\footnotetext{
* Correspondence: ctlee@snu.ac.kr

'Division of Pulmonary and Critical Care Medicine, Department of Internal

Medicine, Seoul National University Bundang Hospital, Seongnam, Korea

${ }^{2}$ Department of Internal Medicine, Seoul National University Bundang

Hospital, 173-82 Gumi-Ro, Bundang-Gu, Seongnam 464-707, Korea

Full list of author information is available at the end of the article
}

Nodular GGOs can be found in eosinophilic lung disease, pulmonary lymphoproliferative disorder, and interstitial fibrosis, with a persistent nGGO being a possible sign of early lung cancer [3]. The natural development of nGGO follows a stepwise progression from atypical adenomatous hyperplasia (AAH) to adenocarcinoma in situ (AIS: formerly bronchioloadenocarcinoma), to microinvasive adenocarcinoma (MIA), and finally to invasive adenocarcinoma (IA) [4]. However, some adenocarcinomas do not follow this pathway, manifesting as consolidation and/or solid mass, with different genetic profiles. Therefore, lung adenocarcinoma exhibits heterogeneity in pathogenesis and progression [5].

Several driver mutations have been identified in lung cancer, such as epidermal growth factor receptor (EGFR) and K-ras mutations and anaplastic lymphoma kinase

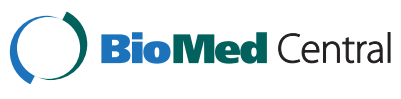

(c) 2014 Ko et al.; licensee BioMed Central Ltd. This is an Open Access article distributed under the terms of the Creative Commons Attribution License (http://creativecommons.org/licenses/by/4.0), which permits unrestricted use, distribution, and reproduction in any medium, provided the original work is properly credited. The Creative Commons Public Domain Dedication waiver (http://creativecommons.org/publicdomain/zero/1.0/) applies to the data made available in this article unless otherwise stated. 
$(A L K)$ rearrangement. Lung cancers expressing EGFR mutations respond well to the EGFR tyrosine kinase inhibitors [6-8]. The fusion of echinoderm microtubuleassociated protein-like $4(E M L 4)$ and $A L K$ gene by rearrangement in non-small cell lung cancer was identified [9] and developed as a target of the ALK tyrosine kinase inhibitor, crizotinib $[10,11]$. These biomarkers predict response to these molecular targeting agents and testing for these markers is recommended in lung cancer patients [12,13], enabling personalized medicine for patients harboring EGFR mutations or $A L K$ gene rearrangements. It is therefore very important to investigate the frequencies and clinical implications of these driver mutations in nGGOs, a specific type of lung adenocarcinoma.

Many studies have reported that EGFR mutations are frequent in lung cancer with nGGOs, even in precancerous lesions such as AAH [14-17]; however, the role of $A L K$ rearrangement in $\mathrm{nGGOs}$ remains unknown. We analyzed patients with lung cancer with nodular GGOs to investigate the correlation between biomarker status and clinicopathological and radiologic characteristics and to determine the roles of $A L K$ rearrangements and EGFR mutations in nGGOs.

\section{Methods}

\section{Patients}

Among the patients who underwent surgical resection of their CT-identified nGGOs between August 2008 and March 2013 at Seoul National University Bundang Hospital (SNUBH), we selected patients who were diagnosed with lung cancer by pathologic confirmation of the surgical specimen. Multiple nGGOs in a single patient were considered different cases of nGGO. Patient data were extracted from medical records, including those pertaining to the age at the time of surgery, sex, smoking history quantified by packs per year, tumor histology, pathologic tumor stage, and biomarker status. This study was approved and individual patient consent waived by the institutional review board of Seoul National University Bundang Hospital (B-1305-202-102).

\section{Radiologic evaluation}

Chest CT scans were performed preoperatively in each patient. All CT images were reviewed with a pulmonary window setting (window width, $2000 \mathrm{HU}$; window level, $-500 \mathrm{HU}$ ) and mediastinal window setting (window width $440 \mathrm{HU}$, window level $45 \mathrm{HU}$ ). GGOs appear in pulmonary window images of chest $\mathrm{CT}$, but disappear on mediastinal window images [3]. We included all nodules that contained any amount of GGO.

To evaluate the proportion of the solid component in the nGGOs, we measured the maximum transverse diameter (Tmax) and maximum perpendicular diameter (Pmax) of both the pulmonary and mediastinal window settings (pTmax, mTmax, pPmax, mPmax) and calculated the tumor shadow disappearance rate (TDR) in all nGGOs. TDR was calculated using the following formula: $\mathrm{TDR}=1-(\mathrm{mTmax} \times \operatorname{mPmax} / \mathrm{pTmax} \times \mathrm{pPmax})[18]$.

\section{Histopathology review}

Surgical specimens were reviewed by an experienced pathologist (J-H Chung) and another pathologist ( $\mathrm{H} \mathrm{Kim}$ ). TNM classification was performed according to the Union for International Cancer Control and the American Joint Committee on Cancer staging system, 7th edition [19]. In some participants, lymph node dissection was not performed because lymphatic invasion was deemed unlikely in the preoperative evaluation; these participants were considered N0 stage. Lung cancer was histologically classified as adenocarcinoma or squamous cell carcinoma. The majority of participants were diagnosed with adenocarcinoma and were categorized according to the 2011 International Association for the Study of Lung Cancer/American Thoracic Society/European Respiratory Society (IASLC/ATS/ERS) classification system as adenocarcinoma in situ (AIS), minimally invasive adenocarcinoma (MIA), and various types of invasive adenocarcinoma (IA) [4].

\section{Molecular analysis}

We analyzed the samples for EGFR mutation and $A L K$ rearrangements. Genomic DNA was extracted from formalin-fixed paraffin-embedded specimens. Exons 1821 of the EGFR gene were analyzed by PCR amplification and sequencing with an ABI Prism 3100 DNA analyzer and standard protocols. Peptide nucleic acid (PNA)-mediated PCR clamping or pyrosequencing methods are more sensitive than direct sequencing (DS) for EGFR mutation detection [20], but we have found that all of these methods are appropriate when sufficient tumor cells are properly micro-dissected and analyzed within a meticulously controlled turnaround time at a single institute (SNUBH) [21]. We included only nGGO specimens resected en bloc to ensure sufficient tumor cell sampling; this is the main strength of this study, as it provided highly accurate DS detection of EGFR mutations.

To detect $A L K$ rearrangements, we first screened the tissues by immunohistochemistry (IHC) with monoclonal anti-ALK antibody (clone 5A4, Novocastra, 1:30, Newcastle, UK) and classified them with a four-tiered scoring system: $0,+1,+2$, and +3 . For cases with IHC scores of +2 or +3 , fluorescence in situ hybridization (FISH) was used to detect $A L K$ translocation by previously reported methods [22,23]. Concordance between IHC and FISH is high; thus, it is appropriate to use the sensitive IHC method for screening and FISH as a standard diagnostic test to detect $A L K$ rearrangements [24]. 


\section{Statistical analysis}

Statistical analysis was performed in SPSS version 18.0 for Windows (SPSS Inc., Chicago, IL). Numerical variables are expressed as mean \pm standard deviation. All statistical tests were two-sided, and differences were considered statistically significant at $\mathrm{P}<0.05$.

\section{Results}

\section{Patient characteristics}

We recruited 289 patients who underwent surgical treatment for nGGOs from August 2009 to March 2013 at SNUBH. After pathologic confirmation of the surgical specimens, nine patients were excluded with diagnoses of non-cancerous lung conditions, including three interstitial fibroses, two lymphoplasma cell infiltrations, two chronic inflammations, one anthracofibrotic nodule, and one AAH. The remaining 280 nGGOs in 261 patients were considered lung cancer, including adenocarcinoma, squamous cell carcinoma, and adenosquamous carcinoma. We excluded 63 nGGOs in 46 patients for whom $E G F R$ and/or $A L K$ status was unavailable. Finally, 217 nGGO lesions in 215 patients were enrolled. Two patients had multiple nGGO lesions, which were tested for biomarker status. All nodules were diagnosed as adenocarcinoma, except one, which was identified as adenosquamous carcinoma.

\section{Pathologic classification of GGO nodules}

Pathologic findings of 217 nGGOs were classified according to the 2011 IASLC/ATS/ERS classification. Numbers of AIS, MIA, and IA were 15,16 , and 185 , respectively, and there was one adenosquamous carcinoma. Acinar predominant adenocarcinoma was the most frequent type in nGGOs. Seven solid predominant adenocarcinomas and five invasive mucinous adenocarcinomas also presented as nodules with GGOs. Six $A L K$ rearrangement-positive (ALK-positive) nGGOs were invasive adenocarcinomas, whereas $11.8 \%$ (14 out of 119) of EGFR mutation-positive nGGOs were pre-invasive or minimally invasive adenocarcinomas. Subtypes of invasive adenocarcinoma revealed no statistical difference between $A L K$ rearrangement and EGFR mutation-positive nGGOs (Table 1).

\section{Analysis of ALK- and EGFR mutation-positive nodules}

FISH identified $A L K$ rearrangements in six lesions (2.8\%) and EGFR mutations in 119 lesions (54.8\%). These driver gene mutations were mutually exclusive in the examined nGGOs.

\section{ALK-positive GGO nodules}

Histopathology revealed that patients with $A L K$-positive nGGOs exhibited more advanced disease stages according to the AJCC, 7th edition ( $\mathrm{p}=0.018$ ) (Table 2). ALK-positive nodules were significantly larger than $A L K$-negative
Table 1 Pathologic classification of GGO nodules according to the IASLC/ATS/ERS criteria, 2011

\begin{tabular}{|c|c|c|c|}
\hline & Number & ALK positive & EGFR positive \\
\hline Total & 217 & 6 & 119 \\
\hline Adenocarcinoma in situ & 15 & 0 & 3 \\
\hline $\begin{array}{l}\text { Minimally invasive } \\
\text { adenocarcinoma }\end{array}$ & 16 & 0 & 11 \\
\hline \multicolumn{4}{|l|}{ Invasive adenocarcinoma } \\
\hline Lepidic predominant & 36 & 1 & 19 \\
\hline Acinar predominant & 93 & 3 & 53 \\
\hline Papillary predominant & 42 & 1 & 28 \\
\hline $\begin{array}{l}\text { Micropapillary } \\
\text { predominant }\end{array}$ & 1 & 0 & 1 \\
\hline Solid predominant & 7 & 1 & 3 \\
\hline \multicolumn{4}{|l|}{$\begin{array}{l}\text { Variants of invasive } \\
\text { adenocarcinoma }\end{array}$} \\
\hline $\begin{array}{l}\text { Invasive mucinous } \\
\text { adenocarcinoma }\end{array}$ & 5 & 0 & 0 \\
\hline Enteric & 1 & 0 & 0 \\
\hline Adenosquamous carcinoma & 1 & 0 & 1 \\
\hline
\end{tabular}

Table 2 Clinicopathological characteristics according to $A L K$ rearrangement status

\begin{tabular}{|c|c|c|c|}
\hline & ALK positive & ALK negative & $P$ value \\
\hline $\mathrm{N}$ & 6 & 211 & \\
\hline Age & $60.00 \pm 12.05$ & $63.22 \pm 10.13$ & 0.579 \\
\hline $\operatorname{Sex}(M: F)$ & $2: 4$ & $96: 115$ & 0.692 \\
\hline PYR & $0.750 \pm 1.173$ & $9.769 \pm 17.381$ & 0.464 \\
\hline Pathologic stage & 6 & $206^{*}$ & 0.018 \\
\hline 0 & 0 & 15 & \\
\hline IA & 1 & 143 & \\
\hline IB & 3 & 33 & \\
\hline$\| A$ & 1 & 5 & \\
\hline$\| \mathrm{B}$ & 0 & 2 & \\
\hline$\| \mathrm{A}$ & 1 & 7 & \\
\hline IIIB & 0 & 1 & \\
\hline Nodal involvement & 2 & 13 & 0.060 \\
\hline Histologic invasiveness & 6 & $210+$ & 0.554 \\
\hline AIS & 0 & 15 & \\
\hline MIA & 0 & 16 & \\
\hline $\mid A$ & 6 & 179 & \\
\hline Maximal diameter & $33.583 \pm 13.736$ & $22.528 \pm 10.690$ & 0.037 \\
\hline Solid diameter & $23.217 \pm 16.906$ & $11.452 \pm 10.920$ & 0.039 \\
\hline TDR & $0.533 \pm 0.327$ & $0.700 \pm 0.290$ & 0.209 \\
\hline
\end{tabular}

*Data for pathologic stage were unavailable for 5 patients. tData for histologic invasiveness were unavailable for 1 patient. 
nodules $(\mathrm{p}=0.037)$. The solid proportion of $A L K$-positive nodules was also significantly larger than that of $A L K$ negative nodules $(\mathrm{p}=0.039)$. All $A L K$-positive nodules were IA according to the 2011 IASLC/ATS/ERS classification; three nGGOs were acinar predominant subtypes, one was the solid subtype, one was the lepidic subtype, and one was the papillary predominant subtype (Table 1). Three nodules showed cribriform features and one nodule showed a signet ring cell pattern.

\section{EGFR mutation-positive GGO nodules}

$E G F R$ mutations were more frequent in women $(\mathrm{p}=$ $0.004)$ and in non-smokers or light smokers $(\mathrm{p}<0.001)$. nGGOs with EGFR mutations did not significantly nonmutated lesions in terms of nodule size, solid proportion, nodal involvement, pathologic stage, and histologic invasiveness (Table 3). Among nGGO lesions with EGFR mutations, 56 nodules had a point mutation in exon 21 (L858R mutation in 54, L861Q in 1, and G863C in 1). Patients with EGFR mutations in exon 21 were older than patients with wild-type EGFR lesions $(\mathrm{p}=0.034)$, were more likely to be non-smokers or light smokers $(\mathrm{p}=$ $0.002)$, and were more frequently women $(\mathrm{p}=0.001)$. Patients with EGFR mutations in exons 19 or 20 showed no

Table 3 Clinicopathological characteristics according to EGFR mutation status

\begin{tabular}{|c|c|c|c|}
\hline & EGFR positive & EGFR negative & $P$ value \\
\hline $\mathrm{N}$ & 119 & 98 & \\
\hline Age & $63.50 \pm 9.11$ & $62.68 \pm 11.35$ & 0.559 \\
\hline $\operatorname{Sex}(M: F)$ & $43: 76$ & $55: 43$ & 0.003 \\
\hline PYR & $5.805 \pm 14.426$ & $14.031 \pm 19.193$ & $<0.001$ \\
\hline Pathologic stage & $117^{*}$ & $95^{*}$ & 0.199 \\
\hline 0 & 6 & 9 & \\
\hline IA & 87 & 57 & \\
\hline $\mathrm{IB}$ & 18 & 18 & \\
\hline$\| A$ & 1 & 5 & \\
\hline$\| B$ & 2 & 0 & \\
\hline$\| \mathrm{A}$ & 3 & 5 & \\
\hline IIIB & 0 & 1 & \\
\hline Nodal involvement & 5 & 10 & 0.106 \\
\hline Histologic invasiveness & $118+$ & 98 & 0.600 \\
\hline AIS & 6 & 9 & \\
\hline MIA & 11 & 5 & \\
\hline IA & 101 & 84 & \\
\hline Maximal diameter & $22.387 \pm 9.876$ & $22.376 \pm 12.052$ & 0.507 \\
\hline Solid diameter & $11.133 \pm 11.229$ & $12.559 \pm 11.257$ & 0.353 \\
\hline TDR & $0.702 \pm 0.295$ & $0.687 \pm 0.290$ & 0.720 \\
\hline
\end{tabular}

*Data for pathologic stage were unavailable for 2 EGFR positive and 3 EGFR negative patients.

tData for histologic invasiveness were unavailable for 1 patient. significant clinicopathological and radiologic differences in comparison to those without EGFR mutations (Table 4).

\section{Comparison between groups with distinct molecular biomarkers}

No significant demographic differences were found between the two molecular biomarker groups. Interestingly, nGGOs with $A L K$ rearrangement were associated with significantly higher pathologic stage and larger maximal and solid diameter in comparison to nGGO lesions with EGFR mutation, but not in TDR. All $A L K$-positive nodules were classified as IA, but this trend was not significant due to the relatively small sample size (Table 5).

\section{Comparison of EGFR mutation and ALK rearrangement rate in GGO nodules to previous studies of a large cohort of adenocarcinomas}

The prevalence of EGFR and $A L K$ mutations in GGO nodules in this study was compared to previous reports of adenocarcinoma of all types. As summarized in Table 6 the $A L K$ rearrangement rate $(2.8 \%)$ in this study was quite low. We previously reported an $A L K$ rearrangement rate of $6.8 \%$ in all types of adenocarcinoma [23]. Other reports from Korean institutes showed higher rates of $A L K$ rearrangement [5.4\% [25] and 20.4\% [26]]; however, no significant difference was found in EGFR mutation rate.

\section{Discussion}

Lung cancer, in its early stage, can present as nGGOs on chest CT. Lung adenocarcinoma with growth patterns involving the alveolar septum and a relative lack of acinar filling shows GGOs on chest CT, and a high GGO proportion is correlated with good prognosis [27]. Pathology of GGO nodules has shown that the proportion of GGO in nodular adenocarcinomas decreases through the AAH-AIS-MIA-IA pattern of progression [28], and that GGO nodules must undergo in situ changes, since AIS (formerly called BAC) and precancerous lesions such as AAH correspond to pure GGO [15].

The clinicopathologic, radiologic, and molecular biological characteristics of nGGOs are important for our understanding of the mechanism of carcinogenesis and for predicting the chemotherapeutic response. Since the introduction of molecular targeting agents, many groups have studied the EGFR mutation status of nGGOs, but there is little data on $A L K$ rearrangements in nGGOs. $E G F R$ mutations are frequently found in the early stages of nGGO, such as in AAH and AIS, and play an important role in the pathogenesis of adenocarcinoma with GGO patterns. However, the role of $A L K$ rearrangement, another potent driver mutation in adenocarcinoma, has not been described in GGO nodules. 
Table 4 Clinicopathological characteristics according to EGFR mutation type

\begin{tabular}{|c|c|c|c|c|}
\hline & EGFR exon 19 & EGFR exon 20 & EGFR exon 21 & EGFR negative \\
\hline N & 50 & 9 & 56 (L858R in 54) & 98 \\
\hline Age & $60.40 \pm 8.83$ & $64.22 \pm 8.04$ & $66.45 \pm 8.80^{* *}$ & $62.68 \pm 11.35$ \\
\hline Sex & $M: F=23: 27$ & $M: F=4: 5$ & $M: F=16: 40^{* *}$ & $55: 43$ \\
\hline PYR & $8.09 \pm 14.90$ & $2.72 \pm 6.55$ & $4.68 \pm 15.25^{* *}$ & $14.03 \pm 19.19$ \\
\hline Pathologic stage & 50 & 9 & $54^{*}$ & 95 \\
\hline 0 & 4 & 0 & 2 & 9 \\
\hline IA & 40 & 6 & 38 & 57 \\
\hline $\mathrm{IB}$ & 4 & 2 & 12 & 18 \\
\hline$\| \mathrm{A}$ & 0 & 0 & 1 & 5 \\
\hline$\| B$ & 1 & 1 & 0 & 0 \\
\hline$\| \mathrm{A}$ & 1 & 0 & 1 & 5 \\
\hline$\| I \mid B$ & 0 & 0 & 0 & 1 \\
\hline Nodal involvement & 1 & 1 & 2 & 10 \\
\hline Histologic invasiveness & 50 & 9 & $55+$ & 98 \\
\hline AIS & 4 & 0 & 2 & 9 \\
\hline MIA & 7 & 0 & 4 & 5 \\
\hline IA & 39 & 9 & 49 & 84 \\
\hline Maximal diameter & $21.294 \pm 10.713$ & $26.944 \pm 12.692$ & $22.950 \pm 8.769$ & $22.376 \pm 12.052$ \\
\hline Solid diameter & $9.392 \pm 11.754$ & $16.489 \pm 15.322$ & $11.900 \pm 10.303$ & $12.559 \pm 11.257$ \\
\hline TDR & $0.765 \pm 0.283$ & $0.592 \pm 0.312$ & $0.679 \pm 0.296$ & $0.692 \pm 0.292$ \\
\hline
\end{tabular}

*Data for pathologic stage were unavailable for 2 patients. tData for histologic invasiveness were unavailable for 1 patient. **P value $<0.05$ compared with EGFR-negative patients.

In this study, we investigated the frequencies and clinicopathological characteristics of driver mutations, focusing on $A L K$ rearrangement in resected adenocarcinoma with GGO patterns. To our knowledge, this is the largest comprehensive analysis of lung cancer presenting as GGO nodules. We included lung cancer nodules exhibiting any amount of GGO regardless of its size, thereby investigating the molecular biomarker status of lung cancer at early stages.

Adenocarcinoma with $A L K$ rearrangement is usually found in younger, female patients who have light to no smoking history, and has been reported to have acinar, papillary, cribriform, and signet-ring patterns. The radiological characteristics of lung cancer with $A L K$ rearrangement have hardly been studied, and there is a lack of data concerning the role of $A L K$ rearrangement in nGGO lesions. In one study, Fukui et al. reported that no GGO nodules were found in patients with $A L K$ rearrangement while $50 \%$ of adenocarcinomas that did not have $A L K$ rearrangement also had GGO nodules and also $E M L 4-A L K$-positive tumors mainly exhibited a solid pattern on CT [29].

In this study, the proportion of $A L K$-positive nGGO lesions was significantly lower $(2.8 \%)$ than that obtained in previous studies of a large cohort of adenocarcinomas
(3.9-20.4\%) (Table 6) [23,25,26,29-32], and was significantly lower than the $6.8 \%$ of 395 resected adenocarcinoma patients in our previous study, which included all types of curatively resected adenocarcinoma [23]. This could be indirect evidence of the lower incidence of $A L K$ rearrangements in adenocarcinomas with GGO patterns compared to adenocarcinomas of all types.

It is well known that $A L K$-positive adenocarcinoma is likely to present a signet-ring cell or cribriform pattern and abundant mucin production on histological analysis [33,34]: $A L K$-positive lesions are observed as a solid, rather than a GGO, nodule $[29,35,36]$. This explains the low proportion of $A L K$-positive patients in this study, which focuses on nGGOs. Fukui et al. studied the radiologic characteristics of $28 A L K$-positive adenocarcinomas and revealed no GGO portion [29] and another report on CT characteristics of ALK rearranged advanced NSCLC from Japan also report low frequency of ALK rearrangement (one among 36 cases) [36], consistent with our findings.

We revealed that maximal diameters and the solid portion of nGGOs with $A L K$ rearrangement were significantly larger than were those without $A L K$ rearrangement. All nGGOs with $A L K$ rearrangement were IA (invasive adenocarcinoma) with acinar predominant 
Table 5 Clinicopathological characteristics according to molecular biomarkers in nGGO

\begin{tabular}{|c|c|c|c|}
\hline & EGFR & $A L K$ & P value* \\
\hline $\mathrm{N}$ & 119 & 6 & \\
\hline Age & $63.50 \pm 9.11$ & $60.00 \pm 12.05$ & 0.571 \\
\hline Sex & $M: F=43: 76$ & $M: F=2: 4$ & 0.889 \\
\hline PYR & $5.805 \pm 14.426$ & $0.750 \pm 1.173$ & 0.942 \\
\hline Pathologic stage & $117+$ & 6 & 0.001 \\
\hline 0 & 6 & 0 & \\
\hline $\mid \mathrm{A}$ & 87 & 1 & \\
\hline IB & 18 & 3 & \\
\hline$\| \mathrm{A}$ & 1 & 1 & \\
\hline$\| B$ & 2 & 0 & \\
\hline$\| \mathrm{A}$ & 3 & 1 & \\
\hline$\| \mathrm{IIB}$ & 0 & 0 & \\
\hline Nodal involvement & 5 & 2 & 0.003 \\
\hline Histologic invasiveness & $118^{* *}$ & 6 & 0.351 \\
\hline AIS & 6 & 0 & \\
\hline MIA & 11 & 0 & \\
\hline $\mid A$ & 101 & 6 & \\
\hline Maximal diameter & $22.387 \pm 9.876$ & $33.583 \pm 13.736$ & 0.032 \\
\hline Solid diameter & $11.133 \pm 11.229$ & $23.217 \pm 16.906$ & 0.032 \\
\hline TDR & $0.702 \pm 0.295$ & $0.533 \pm 0.327$ & 0.225 \\
\hline
\end{tabular}

*P value: EGFR vs. ALK.

†Data for pathologic stage were unavailable for 2 patients.

**Data for histologic invasiveness were unavailable for 1 patient. subtypes $(\mathrm{n}=3)$ and three with cribriform pattern. Patients with $A L K$-positive lesions showed more advanced pathologic stages than those with EGFR-positive GGOs. Therefore, we suggest $A L K$ rearrangement is associated with cellular and histological type as well as clinical aggressiveness.

Several studies have revealed that adenocarcinomas with $A L K$ rearrangement have more lymph node metastases $[23,25]$. Combined with the radiological characteristics discussed above, the $A L K$-positive adenocarcinoma seems not to follow the stepwise carcinogenesis pattern of AAH-AIS-MIA-IA, but to grow rapidly and bypass the phase of lepidic growth. This assumption is consistent with the histological analysis of $A L K$-positive adenocarcinomas showing lower frequencies of lepidic growth and AAH/BAC (AIS) in the background of $A L K$-positive lung adenocarcinomas [35].

Distinct subsets of adenocarcinoma with morphologic differentiation to type II pneumocytes, Clara cells, or non-ciliated bronchioles are thought to originate from the terminal respiratory unit (TRU), and EGFR mutation is involved with early-stage carcinogenesis of TRU-type adenocarcinoma [5,37]; nGGOs appear to be another marker of TRU-type adenocarcinoma [5].

Thyroid transcription factor-1 (TTF-1) is a marker of TRU-type adenocarcinoma [37,38], and two studies concerning 11 and $12 A L K$-positive patients each revealed TTF-1 positivity in all $A L K$-positive adenocarcinomas $[26,39]$. This finding suggests that this subtype of adenocarcinoma may have TRU-origin histogenesis [39]. However, the low proportion of GGO with $A L K$ rearrangement and the advanced stage in ALK-positive nGGOs found in

Table 6 Prevalence of biomarker mutations in previous large population studies of lung adenocarcinoma

\begin{tabular}{|c|c|c|c|c|c|}
\hline Molecular biomarker & Author (reference) & Frequency & Total number & Population & Remarks \\
\hline \multirow[t]{8}{*}{$A L K$} & Paik et al. [23] & $6.8 \%$ & 395 & Korean & Surgically resected \\
\hline & Choi et al. [25] & $5.4 \%$ & 331 & Korean & Underwent FDG-PET \\
\hline & Koh et al. [26] & $20.4 \%$ & 221 & Korean & Advanced disease \\
\hline & Takeuchi et al. [31] & $3.9 \%$ & 1121 & Japanese & Surgically resected \\
\hline & Fukui et al. [29] & $3.9 \%$ & 720 & Japanese & Surgically resected \\
\hline & Wang et al. [32] & $8.6 \%$ & 151 & Chinese & Advanced disease \\
\hline & Rodig et al. [30] & $5.6 \%$ & 358 & American & Surgically resected, partially \\
\hline & This study & $2.8 \%$ & 217 & Korean & nGGO only \\
\hline \multirow[t]{8}{*}{ EGFR } & Choi et al. [25] & $47.1 \%$ & 331 & Korean & Underwent FDG-PET \\
\hline & Kim et al. [46] & $43.5 \%$ & 200 & Korean & - \\
\hline & Sun et al. [49] & $53.1 \%$ & 358 & Korean & - \\
\hline & Kosaka et al. [47] & $49.1 \%$ & 224 & Japanese & Surgically resected \\
\hline & Uramoto et al. [50] & $37.8 \%$ & 437 & Japanese & Surgically resected \\
\hline & Huang et al. [45] & $38.1 \%$ & 858 & Chinese & - \\
\hline & Liam et al. [48] & $39.5 \%$ & 812 & Malaysian & - \\
\hline & This study & $54.8 \%$ & 217 & Korean & nGGO only \\
\hline
\end{tabular}


this study indicates that it is still possible that this subtype may not follow a process of TRU origin. Further pathologic analysis of morphological characteristics is required.

Because the prevalence of adenocarcinoma with $A L K$ rearrangement is low compared to EGFR mutation, studies investigating various characteristics of $A L K$-positive lung cancer do not gather enough participants to yield consistent results. Previous studies on a large, unselected population of adenocarcinoma with $A L K$ rearrangement reported that patients with $A L K$-positive lung cancer were younger $[23,29,30,32]$, female $[23,25,40]$, and light or non-smokers [23,25,29,30,32,40,41]. We previously reported that $A L K$-rearranged lung adenocarcinomas of all radiologic types showed higher stage at diagnosis and more solid pattern, were more cribriform, and had a closer relationship with adjacent bronchioles [42] and more frequently positive bronchoscopic findings than EGFR-positive lung adenocarcinoma [43], which suggested more proximal origin of ALK rearranged lung adenocarcinoma than EGFR-positive adenocarcinoma. These findings were consistent with low frequency of ALK rearrangement in nGGOs which presented in peripheral location.

We found no correlation between age, sex, smoking status, and $A L K$ positivity, probably due to the small number of $A L K$-positive patients and the weak representation of adenocarcinoma, since we enrolled only patients with nGGOs.

We found that EGFR mutation was associated with female, never/light smokers, as expected [44]. The frequency of EGFR mutation in nGGOs in this study was $54.8 \%$, which was relatively high in comparison to other, large cohorts of adenocarcinoma [25,45-50] (Table 6). However, we could not predict EGFR mutation status by the GGO proportion of nodules or tumor size. EGFR mutation status was not associated with pathologic stage, nodal involvement, or histologic invasiveness.

It is interesting that after stratifying EGFR mutations in exons 19, 20, and 21, only the mutation in exon 21 (mostly L858R) correlated with female gender and never/light smoking status. This result is consistent with other studies of the characteristics of adenocarcinoma and EGFR mutation type [51,52]. The association between $E G F R$ and female non- or light smoker may be limited to EGFR mutation in exon 21.

According to large cohort studies, EGFR mutations and $A L K$ rearrangements are mutually exclusive. However, several cases of co-incident EGFR mutation and $A L K$ rearrangement have been reported, most of which demonstrated good response to EGFR tyrosine kinase inhibitors [32]. In our study, which recruited participants at the early stage of adenocarcinoma, these molecular biomarkers were mutually exclusive. It is thought that they act through different mechanisms in early carcinogenesis.
The major strength of study is that it is the largest cohort concerning lung cancer with nGGOs. All nodules were resected by curative surgery, which reinforced the accuracy of pathologic and molecular diagnoses of the surgical specimens. Although we collected enough GGO nodules with EGFR mutations in exons 19 and 21, we could not collect sufficient numbers of samples with $A L K$ rearrangement due to the inherent limitation that adenocarcinoma with $A L K$ rearrangement tends to present as solid nodules in chest CT.

\section{Conclusions}

$A L K$ rearrangement is rare in lung adenocarcinoma presenting as nGGOs and is associated with a more advanced stage and larger tumor size, suggesting a distinct origin and an aggressive nature in the progression of lung adenocarcinoma. $A L K$ rearrangement may not play an important role in the early pathogenesis of nGGO. It is important to understand the clinicopathological characteristics of nGGOs associated with each driver mutation, as well as their radiologic correlations, when individualizing lung cancer treatments with moleculartargeted therapies.

\section{Abbreviations \\ EGFR: Epidermal growth factor receptor; ALK: Anaplastic lymphoma kinase; nGGO: Nodular ground glass opacity; CT: Computed tomography; \\ SPN: Solitary pulmonary nodule; AAH: Atypical adenomatous hyperplasia; AIS: Adenocarcinoma in situ, MIA, microinvasive adenocarcinoma; IA: Invasive adenocarcinoma; TDR: Tumor shadow disappearance rate; \\ IHC: Immunohistochemistry; FISH: Fluorescent in situ hybridization; TRU: Terminal respiratory unit; TTF-1: Thyroid transcription factor-1.}

\section{Competing of interest}

The authors state that they have no conflict of interest to disclose.

\section{Authors' contributions}

SJK and CTL had full access to data, writing, and responsibility for the manuscript. YJL, JSP, YJC, HIY, and JHL assisted with recruitment and critical reading of the manuscript. JHC examined the pathology and analyzed EGFR and ALK status. HK reviewed the pathologic specimen. TJK and KWL analyzed radiological characteristics of nGGOs. KK and SJ performed surgical resection of nGGOs. All authors read and approved the final manuscript.

\section{Acknowledgement}

We also appreciated CS Leem for managing data base of cancer registry of $\mathrm{SNUBH}$. We thank Editage, Korea for providing proofreading and medical editing of this manuscript.

\section{Author details}

'Division of Pulmonary and Critical Care Medicine, Department of Internal Medicine, Seoul National University Bundang Hospital, Seongnam, Korea. ${ }^{2}$ Department of Internal Medicine, Seoul National University Bundang Hospital, 173-82 Gumi-Ro, Bundang-Gu, Seongnam 464-707, Korea.

${ }^{3}$ Department Pathology, Seoul National University College of Medicine, Seongnam, Korea. ${ }^{4}$ Department of Radiology, Seoul National University Bundang Hospital, Seongnam, Korea. ${ }^{5}$ Department of Thoracic and Cardiovascular Surgery, Seoul National University Bundang Hospital, Seongnam, Korea. ${ }^{6}$ Department of Pathology, Seoul National University Hospital, Seoul, Korea.

Received: 19 March 2014 Accepted: 24 April 2014

Published: 3 May 2014 


\section{References}

1. Aberle DR, Adams AM, Berg CD, Black WC, Clapp JD, Fagerstrom RM, Gareen IF, Gatsonis C, Marcus PM, Sicks J: Reduced lung-cancer mortality with low-dose computed tomographic screening. N Engl J Med 2011, 365(5):395-409.

2. Godoy MC, Naidich DP: Subsolid Pulmonary Nodules and the Spectrum of Peripheral Adenocarcinomas of the Lung: Recommended Interim Guidelines for Assessment and Management. Radiology 2009, 253(3):606-622.

3. Lee HY, Lee KS: Ground-glass opacity nodules: histopathology, imaging evaluation, and clinical implications. J Thorac Imaging 2011, 26(2):106-118.

4. Travis WD, Brambilla E, Noguchi M, Nicholson AG, Geisinger KR, Yatabe $Y$, Beer DG, Powell CA, Riely GJ, Van Schil PE, Garg K, Austin JH, Asamura H, Rusch WW, Hirsch FR, Scagliotti G, Mitsudomi T, Huber RM, Ishikawa Y, Jett J, Sanchez-Cespedes M, Sculier JP, Takahashi T, Tsuboi M, Vansteenkiste J, Wistuba I, Yang PC, Aberle D, Brambilla C, Flieder D, et al: International Association for the Study of Lung Cancer/American Thoracic Society/European Respiratory Society international multidisciplinary classification of lung adenocarcinoma. J Thorac Oncol 2011, 6(2):244-285.

5. Takeuchi T, Tomida S, Yatabe Y, Kosaka T, Osada H, Yanagisawa K, Mitsudomi T, Takahashi T: Expression profile-defined classification of lung adenocarcinoma shows close relationship with underlying major genetic changes and clinicopathologic behaviors. J Thorac Oncol 2006, 24(11):1679-1688.

6. Maemondo M, Inoue A, Kobayashi K, Sugawara S, Oizumi S, Isobe H, Gemma A, Harada M, Yoshizawa H, Kinoshita I: Gefitinib or chemotherapy for non-small-cell lung cancer with mutated EGFR. N Engl J Med 2010, 362(25):2380-2388

7. Mitsudomi T, Morita S, Yatabe Y, Negoro S, Okamoto I, Tsurutani J, Seto T, Satouchi M, Tada H, Hirashima T: Gefitinib versus cisplatin plus docetaxel in patients with non-small-cell lung cancer harbouring mutations of the epidermal growth factor receptor (WJTOG3405): an open label, randomised phase 3 trial. Lancet Oncol 2010, 11(2):121-128.

8. Zhou C, Wu YL, Chen G, Feng J, Liu XQ, Wang C, Zhang S, Wang J, Zhou S, Ren S, Lu S, Zhang L, Hu C, Luo Y, Chen L, Ye M, Huang J, Zhi X, Zhang Y, Xiu Q, Ma J, Zhang L, You C: Erlotinib versus chemotherapy as first-line treatment for patients with advanced EGFR mutation-positive non-smallcell lung cancer (OPTIMAL, CTONG-0802): a multicentre, open-label, randomised, phase 3 study. Lancet Oncol 2011, 12(8):735-742.

9. Soda M, Choi YL, Enomoto M, Takada S, Yamashita Y, Ishikawa S, Fujiwara S-i, Watanabe H, Kurashina K, Hatanaka H: Identification of the transforming EML4-ALK fusion gene in non-small-cell lung cancer. Nature 2007, 448(7153):561-566.

10. Kwak EL, Bang Y-J, Camidge DR, Shaw AT, Solomon B, Maki RG, Ou S-HI, Dezube BJ, Jänne PA, Costa DB: Anaplastic lymphoma kinase inhibition in non-small-cell lung cancer. N Engl J Med 2010, 363(18):1693-1703.

11. Shaw AT, Kim D-W, Nakagawa K, Seto T, Crinó L, Ahn M-J, De Pas T, Besse B, Solomon BJ, Blackhall F: Crizotinib versus chemotherapy in advanced ALK-positive lung cancer. N Engl J Med 2013, 368(25):2385-2394.

12. Ettinger DS, Akerley W, Borghaei $H$, Chang AC, Cheney RT, Chirieac LR, D'Amico TA, Demmy TL, Ganti AKP, Govindan R: Non-Small Cell Lung Cancer. J Natl Compr Cancer Netw 2012, 10(10):1236-1271.

13. Lindeman NI, Cagle PT, Beasley MB, Chitale DA, Dacic S, Giaccone G, Jenkins RB, Kwiatkowski DJ, Saldivar J-S, Squire J: Molecular testing guideline for selection of lung cancer patients for EGFR and ALK tyrosine kinase inhibitors: guideline from the College of American Pathologists, International Association for the Study of Lung Cancer, and Association for Molecular Pathology. J Mol Diagn 2013, 15(4):415-453.

14. Aoki $T$, Hanamiya M, Uramoto $H$, Hisaoka M, Yamashita $Y$, Korogi $Y$ : Adenocarcinomas with Predominant Ground-Glass Opacity: Correlation of Morphology and Molecular Biomarkers. Radiology 2012 264(2):590-596

15. Chung J-H, Choe G, Jheon S, Sung S-W, Kim TJ, Lee KW, Lee JH, Lee C-T: Epidermal growth factor receptor mutation and pathologic-radiologic correlation between multiple lung nodules with ground-glass opacity differentiates multicentric origin from intrapulmonary spread. J Thorac Oncol 2009, 4(12):1490-1495.

16. Yoshida $Y$, Kokubu A, Suzuki K, Kuribayashi H, Tsuta K, Matsuno Y, Kusumoto M, Kanai Y, Asamura H, Hirohashi S: Molecular markers and changes of computed tomography appearance in lung adenocarcinoma with ground-glass opacity. Jpn J Clin Oncol 2007, 37(12):907-912.

17. Yano M, Sasaki H, Kobayashi $Y$, Yukiue H, Haneda H, Suzuki E, Endo K, Kawano O, Hara M, Fujii Y: Epidermal growth factor receptor gene mutation and computed tomographic findings in peripheral pulmonary adenocarcinoma. J Thorac Oncol 2006, 1(5):413-416.

18. Okada M, Nishio W, Sakamoto T, Uchino K, Tsubota N: Discrepancy of computed tomographic image between lung and mediastinal windows as a prognostic implication in small lung adenocarcinoma. Ann Thorac Surg 2003, 76(6):1828-1832.

19. Goldstraw P: The 7th Edition of TNM in Lung Cancer: what now? J Thorac Oncol 2009, 4(6):671-673.

20. Kim HJ, Lee KY, Kim Y-C, Kim K-S, Lee SY, Jang TW, Lee MK, Shin K-C, Lee $\mathrm{GH}$, Lee JC: Detection and comparison of peptide nucleic acid-mediated real-time polymerase chain reaction clamping and direct gene sequencing for epidermal growth factor receptor mutations in patients with non-small cell lung cancer. Lung Cancer 2012, 75(3):321-325.

21. Lee HJ, Xu X, Kim H, Jin Y, Sun P, Kim JE, Chung J-H: Comparison of Direct Sequencing, PNA Clamping-Real Time Polymerase Chain Reaction, and Pyrosequencing Methods for the Detection of EGFR Mutations in Non-small Cell Lung Carcinoma and the Correlation with Clinical Responses to EGFR Tyrosine Kinase Inhibitor. Korean J Pathol 2013, 47(1):52-60.

22. Paik JH, Choe G, Kim H, Choe J-Y, Lee HJ, Lee C-T, Lee JS, Jheon S, Chung $\mathrm{J}-\mathrm{H}$ : Screening of anaplastic lymphoma kinase rearrangement by immunohistochemistry in non-small cell lung cancer: correlation with fluorescence in situ hybridization. J Thorac Oncol 2011, 6(3):466-472.

23. Paik JH, Choi C-M, Kim H, Jang SJ, Choe G, Kim DK, Kim HJ, Yoon H, Lee C-T, Jheon S: Clinicopathologic implication of ALK rearrangement in surgically resected lung cancer: a proposal of diagnostic algorithm for ALK-rearranged adenocarcinoma. Lung Cancer 2012, 76(3):403-409.

24. Kim H, Shim HS, Kim L, Kim T-J, Kwon KY, Lee GK, Chung J-H: Guideline Recommendations for Testing of ALK Gene Rearrangement in Lung Cancer: a Proposal of the Korean Cardiopulmonary Pathology Study Group. Korean J Pathol 2014, 48:1-9.

25. Choi H, Paeng JC, Kim D-W, Lee JK, Park CM, Kang KW, Chung J-K, Lee DS: Metabolic and metastatic characteristics of ALK-rearranged lung adenocarcinoma on FDG PET/CT. Lung Cancer 2013, 79(3):242-247.

26. Koh Y, Kim D-W, Kim TM, Lee S-H, Jeon YK, Chung DH, Kim Y-W, Heo DS, Kim W-H, Bang Y-J: Clinicopathologic characteristics and outcomes of patients with anaplastic lymphoma kinase-positive advanced pulmonary adenocarcinoma: suggestion for an effective screening strategy for these tumors. J Thorac Oncol 2011, 6(5):905-912.

27. Aoki T, Tomoda Y, Watanabe H, Nakata H, Kasai T, Hashimoto H, Kodate M, Osaki T, Yasumoto K: Peripheral Lung Adenocarcinoma: Correlation of Thin-Section CT Findings with Histologic Prognostic Factors and Survival. Radiology 2001, 220(3):803-809.

28. Takashima S, Maruyama Y, Hasegawa M, Yamanda T, Honda T, Kadoya M, Sone $\mathrm{S}$ : CT findings and progression of small peripheral lung neoplasms having a replacement growth pattern. Am J Roentgenol 2003, 180(3):817-826.

29. Fukui T, Yatabe Y, Kobayashi Y, Tomizawa K, Ito S, Hatooka S, Matsuo K, Mitsudomi T: Clinicoradiologic characteristics of patients with lung adenocarcinoma harboring EML4-ALK fusion oncogene. Lung Cancer 2012, 77(2):319-325

30. Rodig SJ, Mino-Kenudson M, Dacic S, Yeap BY, Shaw A, Barletta JA, Stubbs $H$, Law K, Lindeman N, Mark E: Unique clinicopathologic features characterize ALK-rearranged lung adenocarcinoma in the western population. Clin Cancer Res 2009, 15(16):5216-5223.

31. Takeuchi K, Soda M, Togashi Y, Suzuki R, Sakata S, Hatano S, Asaka R, Hamanaka W, Ninomiya H, Uehara H: RET, ROS1 and ALK fusions in lung cancer. Nat Med 2012, 18(3):378-381.

32. Wang Z, Zhang $X$, Bai $H$, Zhao J, Zhuo M, An T, Duan J, Yang L, Wu M, Wang S: EML4-ALK rearrangement and its clinical significance in Chinese patients with advanced non-small cell lung cancer. Oncology 2012, 83(5):248-256

33. Pillai RN, Ramalingam SS: The Biology and Clinical Features of Non-small Cell Lung Cancers with EML4-ALK Translocation. Curr Oncol Rep 2012, 14(2):105-110.

34. Jokoji R, Yamasaki T, Minami S, Komuta K, Sakamaki Y, Takeuchi K, Tsujimoto $\mathrm{M}$ : Combination of morphological feature analysis and 
immunohistochemistry is useful for screening of EML4-ALK-positive lung adenocarcinoma. J Clin Pathol 2010, 63(12):1066-1070.

35. Yoshida A, Tsuta K, Nakamura H, Kohno T, Takahashi F, Asamura H, Sekine I, Fukayama M, Shibata T, Furuta K: Comprehensive histologic analysis of ALK-rearranged lung carcinomas. Am J Surg Pathol 2011, 35(8):1226-1234.

36. Park J, Yamaura H, Yatabe Y, Hosoda W, Kondo C, Shimizu J, Horio Y, Yoshida K, Tanaka K, Oguri T, Kobayashi Y, Hida H: Anaplastic lymphoma kinase gene rearrangements in patients with advanced-stage non-smallcell lung cancer: $\mathrm{CT}$ characteristics and response to chemotherapy. Cancer Med 2014, 3(1):118-123.

37. Yatabe Y, Kosaka T, Takahashi T, Mitsudomi T: EGFR mutation is specific for terminal respiratory unit type adenocarcinoma. Am J Surg Pathol 2005, 29(5):633-639.

38. Park WY, Kim MH, Shin DH, Lee JH, Choi KU, Kim JY, Park DY, Lee CH, Sol MY: Ciliated adenocarcinomas of the lung: a tumor of non-terminal respiratory unit origin. Mod Pathol 2012, 25(9):1265-1274.

39. Inamura K, Takeuchi K, Togashi Y, Hatano S, Ninomiya H, Motoi N, Mun M-y, Sakao Y, Okumura S, Nakagawa K: EML4-ALK lung cancers are characterized by rare other mutations, a TTF-1 cell lineage, an acinar histology, and young onset. Mod Pathol 2009, 22(4):508-515.

40. Li Y, Li Y, Yang T, Wei S, Wang J, Wang M, Wang Y, Zhou Q, Liu H, Chen J: Clinical Significance of EML4-ALK Fusion Gene and Association with EGFR and KRAS Gene Mutations in 208 Chinese Patients with Non-Small Cell Lung Cancer. PLoS One 2013, 8(1):e52093.

41. Takahashi T, Kobayashi M, Yoshizawa A, Menju T, Nakayama E: Clinicopathologic features of non-small-cell lung cancer with EML4-ALK fusion gene. Ann Surg Oncol 2010, 17(3):889-897.

42. Kim H, Jang SJ, Chung DH, Yoo SB, Sun P, Jin Y, Nam KH, Paik JH, Chung JH: A comprehensive comparative analysis of the histomorphological features of ALK-rearranged lung adenocarcinoma based on driver oncogene mutations: frequent expression of epithelial-mesenchymal transition markers than other genotype. PLoS One 2013, 8(10):e76999.

43. Kang HJ, Lim HJ, Park JS, Cho YJ, Yoon HI, Chung JH, Lee JH, Lee CT: Comparison of clinical characteristics between patients with ALK-positive and EGFR-positive lung adenocarcinoma. Respir Med 2014, 108(2):388-394

44. Lynch TJ, Bell DW, Sordella R, Gurubhagavatula S, Okimoto RA, Brannigan BW, Harris PL, Haserlat SM, Supko JG, Haluska FG: Activating mutations in the epidermal growth factor receptor underlying responsiveness of non-small-cell lung cancer to gefitinib. N Engl J Med 2004, 350(21):2129-2139.

45. Huang Y-s, Yang J-j, Zhang $X-c$, Yang $X-n$, Huang $Y-j$, Xu C-r, Zhou Q, Wang Z, Su J, Wu Y: Impact of smoking status and pathologic type on epidermal growth factor receptor mutations in lung cancer. Chin Med J 2011, 124(16):2457-2460.

46. Kim HR, Ahn JR, Lee JG, Bang DH, Ha S-J, Hong YK, Kim SM, Nam KC, Rha SY, Soo RA: The Impact of Cigarette Smoking on the Frequency of and Qualitative Differences in KRAS Mutations in Korean Patients with Lung Adenocarcinoma. Yonsei Med J 2013, 54(4):865-874.

47. Kosaka T, Yatabe Y, Endoh H, Kuwano H, Takahashi T, Mitsudomi T: Mutations of the epidermal growth factor receptor gene in lung cancer biological and clinical implications. Cancer Res 2004, 64(24):8919-8923.

48. Liam C-K, Wahid MIA, Rajadurai P, Cheah Y-K, Ng TS-Y: Epidermal Growth Factor Receptor Mutations in Lung Adenocarcinoma in Malaysian Patients. J Thorac Oncol 2013, 8(6):766-772.

49. Sun P-L, Seol H, Lee HJ, Yoo SB, Kim H, Xu X, Jheon S, Lee C-T, Lee J-S, Chung J-H: High Incidence of EGFR Mutations in Korean Men Smokers with No Intratumoral Heterogeneity of Lung Adenocarcinomas: Correlation with Histologic Subtypes, EGFR/TTF-1 Expressions, and Clinical Features. J Thorac Oncol 2012, 7(2):323-330.

50. Uramoto H, So T, Nagata Y, Kuroda K, Shigematsu Y, Baba T, So T, Takenoyama M, Hanagiri T, Yasumoto K: Correlation between HLA alleles and EGFR mutation in Japanese patients with adenocarcinoma of the lung. J Thorac Oncol 2010, 5(8):1136-1142.
51. Hsu K-H, Chen $K-C$, Yang T-Y, Yeh $Y-C$, Chou T-Y, Chen $H-Y$, Tsai C-R, Chen C-Y, Hsu C-P, Hsia J-Y: Epidermal growth factor receptor mutation status in stage I lung adenocarcinoma with different image patterns. J Thorac Oncol 2011, 6(6):1066-1072

52. Lee H-J, Kim YT, Kang CH, Zhao B, Tan Y, Schwartz LH, Persigehl T, Jeon YK, Chung DH: Epidermal Growth Factor Receptor Mutation in Lung Adenocarcinomas: Relationship with CT Characteristics and Histologic Subtypes. Radiology 2013, 268(1):254-264.

doi:10.1186/1471-2407-14-312

Cite this article as: Ko et al.: Epidermal growth factor receptor mutations and anaplastic lymphoma kinase rearrangements in lung cancer with nodular ground-glass opacity. BMC Cancer 2014 14:312.

\section{Submit your next manuscript to BioMed Central and take full advantage of:}

- Convenient online submission

- Thorough peer review

- No space constraints or color figure charges

- Immediate publication on acceptance

- Inclusion in PubMed, CAS, Scopus and Google Scholar

- Research which is freely available for redistribution

Submit your manuscript at www.biomedcentral.com/submit
() Biomed Central 